\title{
Fundamentals of Hermeneutics as A Qualitative Research Theoretical Framework
}

\author{
Mariano D. Gillo
}

\section{ABSTRACT}

\begin{abstract}
This article is written to inspire researchers to use hermeneutics as a qualitative research theoretical framework. Given the extensive scope inherent to this subject matter, it was decided to delimit the discussion to the fundamental information one may seek to know about hermeneutics. Though introductory in nature, it is still hoped that the readers may be able to gain meaningful insights which may serve as a catalyst for understanding this topic. The article has four phases. Phase one traces its historical dimension and presents its varied definitions. Phase two is focused on the four philosophical orientations. Phase three enumerates its contributors and their respective contributions. Phase four elaborates the steps researchers need to undertake when using this framework. This article may be of interest to all academics especially the neophytes who are interested in utilizing hermeneutics either as a method or methodology of a philosophical cum scientific endeavor being undertaken.
\end{abstract}

Keywords: hermeneutics, philosophical orientations, qualitative research framework, theoretical framework.

\section{INTRODUCTION}

One may find it a cliché to start an article by tracing the historical roots of the subject under discussion. But the significance of doing so can certainly never belittled as it provides meaningful insights that may aid towards the full understanding of that subject matter. So, it was decided to first introduce hermeneutics in that manner followed by taking into account the many definitions offered by scholars. Then, the paper advances with a discussion of the four philosophical orientations strongly recognized in this field. Afterwards, the contributions and arguments of the known philosophy think tanks in this field were detailed. Finally, the steps that researchers needed to undergo when using this framework were elaborated.

\section{METHODS}

This paper presents a synthesis of the literature about hermeneutics as a theoretical framework for qualitative research. Data obtained herein were taken from the available sources in the web.

\section{DISCUSSIONS}

\section{A. Meaning and Historical Dimensions of Hermeneutics}

A bulk of literature pinned hermeneutics to have existed in the circulation during the $17^{\text {th }}$ century (Gergen, Hepburn, and Fisher (1986) cited in [1]). Scholars have since associated the
Published Online: June 20, 2021

ISSN: $2736-4534$

DOI : $10.24018 /$ ejedu.2021.2.3.43

\section{Mariano D. Gillo*}

Eastern Visayas State University, Tacloban City, Leyte, The Philippines.

(e-mail: marvycollin @ gmail.com)

*Corresponding Author word to both the Greek verb "hermeneuein" or 'to interpret' and the noun "hermeneia" or 'interpretation' and to Hermes, the messenger and interpreter of knowledge and understanding to the mortals of the Greek gods (Thompson (1990) cited in [2]).

Crotty [3] and The Oxford English Dictionary [4] define hermeneutics as a field of study that deals with the theories and methodological principles of interpretation and explanation especially of Scripture with the ultimate purpose of bringing out its meaning the time it existed. Young [5] however, provided a different perspective of hermeneutics by defining it as a science of interpretation as it is it basically focused and concerned on the methods, problems, and purposes of interpretation. He further argued that hermeneutic deliberately aims to search for exact or precise meaning by taking into account the historical heterogeneity, cultural, language, proximity of time between the author and interpreter, and the contextual dimensions of the text.

Russell [6] on the other hand, claimed that hermeneutics is immensely a group of interpretative approaches to science instead of a singular, completely intact scientific philosophy. Given the varied definitions of hermeneutics, I then define it as a scientific cum philosophical interpretation and understanding of texts contained in both the scripture and behavioral sciences conducted by setting it against history, culture, language, and context as core factors that aid in deciphering process. 


\section{B. Hermeneutics Philosophical Orientations}

Fast forward, in the late $19^{\text {th }}$ century, hermeneutic inquiry formed part of the study of human behavior when philosophers like Wilhelm Dilthey posited that understanding humans should advance from text interpretation to achieving factual knowledge of nature [1]. This contestation had paved the way for the hermeneutics to surface in social sciences which in turn gave birth to four philosophical orientations strongly recognized in this field: hermeneutic divination, reenactment or reproductive hermeneutics, critical hermeneutics, productive or projective hermeneutics [7].

In detail, hermeneutic divination, is credited to Friedreich Schleiermacher. Its basic tenet is that correct text interpretation is achieved by knowing the original intent of the author and the manner of its execution [7]. Hermeneutic reenactment or reproductive hermeneutics, the second philosophical orientation, on the other hand, is a brainchild of W. Dilthey. It puts emphasis on interpretation through bracketing - an act of setting aside prior knowledge and disremembering imaginatively what others may have actually and possibly experience [6]. Meanwhile, the third tradition (i.e., critical hermeneutics) pioneered by Apel and Habermas endorsed the idea of the existence of a 'false consciousness' which as they said, falsify a person's understanding of human experience [6]-[8]. Finally, the productive or projective hermeneutics, commonly associated with Hans-Georg Gadamer, Martin Heidegger. They argued that 'bracketing' prior ideas are beyond possibility as such by innocently reading a text is untrue [7] and that researchers always play a primordial role in extracting meaning in the process of analyzing a text; so, text interpretation then, they claimed, is constructivist in nature which means that it is constructed in the event of the reading process as conducted by the researcher or interpreter [9].

\section{Contributors of Hermeneutics}

Given the philosophical orientations cited above, this paper then preceded by surveying and providing detailed discussions on the philosophical contestations that have been elaborated on, argued for, and variations developed by philosophy think tanks specifically that of Friedrich Schleiermacher, Wilhelm Dilthey, Apel and Habermas, Martin Heidegger and Hans-Georg Gadamer relative to the philosophy of hermeneutic and various methodologies they contested as they appeared in the four philosophical orientations discussed above. The proponents of each of the said philosophical orientations are oftentimes regarded as contributors of hermeneutics.

Let me begin with the arguments of Friedrich Schleiermacher. First, he defined hermeneutics as the art of circumventing misunderstanding. He stands firm for what he believes that every problem of interpretation can be equated to as a problem of understanding. So, he explored understanding relative to how scripture should be figured out, human texts and the manner of communication. He argued that text interpretation must commence by contextualizing the content laid forth in it in terms of its organization. This, he claimed, can be realized by having knowledge of both the grammatical and psychological laws when a researcher attempts to decipher a text and understanding the genuine intent of the author. He then delineated grammatical from psychological interpretation. The former shows the composition or framework of a work from the overall or general ideas of it while the latter is much concerned on the distinct combination that defines the work in its entirety [10].

Meanwhile, Wilhelm Dilthey further elaborated hermeneutics by connecting interpretation to historical objectification. He claimed that understanding starts from an external demonstration of human action and production before one can delve into their interior meaning or what he described as movement pattern (i.e., outer - inner and expression - what is expressed). This, he emphasized cannot be anchored on empathy because empathy involves a direct or forthright identification with the other while interpretation necessitates a mediated understanding which can be achieved by historically contextualizing the text or human expression. He further asserted that understanding is never an attempt of reassembling the intention of the author. His studies on Schleiermacher and his narration on what constitutes understanding on the activity of the religious though became the central idea of his work as regards to the theory and practice of philosophical cum intellectual history. In essence, his primary contribution to religious studies can be traced to his theory of the human studies and its significance for the empirical inquiry on religion. This theory of the human studies as discussed by Dilthey is best understood as an attempt to introduce an idea that these disciplines (i.e., philosophy and religion) have unique subject matter and method that distinguish them from natural sciences. It is categorical then to claim that Dilthey's philosophical work intends to promote a critique of historical reason that would answer questions raised about the possibility of knowledge creation in human science [11].

Apel and Habermas, on the other hand, are the two key proponents who advanced a different version of critical hermeneutics as opposed to that of Gadamer by combining the objective and methodological approaches in attaining important knowledge. Their version of critical hermeneutics emerged in an effort to unravel the nuances behind the distortion of understanding and communication in an ordinary interaction. Scholars regard the critical hermeneutics version of Apel and Habermas as a dialectical social science intended to intercede the objectivity of historical processes including the reasons by those involved. Having an emancipatory effect, they argued that the purpose of social sciences is to advance the processes of self-reflection. So, they claimed that correct understanding of all social action requires critical sciences. They then conceptualized a theory of communication called communicative competence as a normative bedrock for critical theory [12].

Furthermore, Martin Heidegger, a philosopher of German descent, became popularly known for the existential and phenomenological expedition of the question of being. He strongly contended that philosophy is engrossed in what exists and has abandoned the ground of being. He argued that human beings have the inherent belief of living in a world that has since existed but has abandoned the primary question of what being itself is. This question, he said, exemplifies human nature. This philosophical perspective shaped his arguments with regard to hermeneutics. He viewed hermeneutics in a profound manner having veered away from epistemology to ontology [13]. First, he advanced the idea 
that interpretation is altered by the preconceptions of the interpreter and will always form part of its understanding. Furthermore, he contested that interpretation is always a cyclical process which he termed as the hermeneutic circle that is always encapsulated within an excluded possibility of the most elemental type of knowing [14]. The realization of this possibility, he claimed, is achieved by paying a censorious attention to the interplay between what is being interpreted by the interpreter and his preconceptions about it. So, he argued then that the subjective element of interpretation cannot be neglected; therefore, absolute knowledge is impossible to attain. As such, the conflict of interpretation will stand still or remain. In addition, he argued that as Dasien, our meaning is codeveloped by having been born as human and by the experiences and background in life which he claimed is accumulated and determined by a specific culture, gender, and history to which we were 'thrown' or born. This reality, he asserted, facilitates our shared practices and common meanings. Heidegger was first to reject the idea of 'bracketing' of assumptions but promoted instead genuine reflection as a method to achieve awareness of these assumptions. Given these contestations, he defined hermeneutics as a contextual way of interpreting mutual meanings and practices human shared from experiences. Another milestone in the development of hermeneutics was his introduction of the idea of the hermeneutic circle which he defined as a method of understanding our Being-in-theWorld and an approach of expressing and understanding a dialogue [15].

Finally, the perspective of the German philosopher HansGeorg Gadamer on hermeneutics. This philosopher elaborated philosophical hermeneutics. He is known as a front critic on the conventional German perspective to the humanities as well as the modern approaches to humanities that are attuned to natural sciences [16]. His premise behind human understanding is that our consciousness is historically affected that is encapsulated in a specific culture and history. Likewise, he believed in the metaphor of horizon which he succinctly defined as being consciously aware of the limitation of someone's outlook or perspective. Therefore, text interpretation, he said, necessitates a coalition of 'horizon' in which the researcher or interpreter has to put a premium on both the historical context and the background of the text under interpretation [17]. In advancing this idea, he maintained that understanding is always a dialectic, linguistic, and historical undertaking [15]. Just like Heidegger, he also rejected the idea of 'bracketing' which his predecessors believed to be the sole method in maintaining objectivity. Understanding one another, he said, necessitates taking into account experiences in the past because of these same past experiences aid understanding. He promoted dialogue as an ultimate method of unearthing knowledge as it ascertains collusion of the question and answers especially if the persons involved are open or honest, lively engaged, and are interested to arrive at common understanding [18]. Gadamer's proposition on hermeneutics explicitly backs praxis or the merging of theory and practice. Praxis means the entirety of language, knowing, and action. He posited that understanding a text should be construed as an application of knowing how to apply such in our own context. This notion paved the way for the birth of critical hermeneutics which he defined as language interpretation and deliberate examination of omissions. This method promotes the process for critiquing as well as identification of language salient features encapsulated within social and cultural heritages that can be achieved through the interpreter's lens of analysis or horizon [19].

\section{Methods in Hermeneutics}

Hermeneutics. just like other theoretical frameworks, has its unique inherent method in collecting and analyzing data. Patterson \& William [1] and The Qualitative Research Report comprehensively discussed this method. In a nutshell, it is shown in Fig. 1 below.

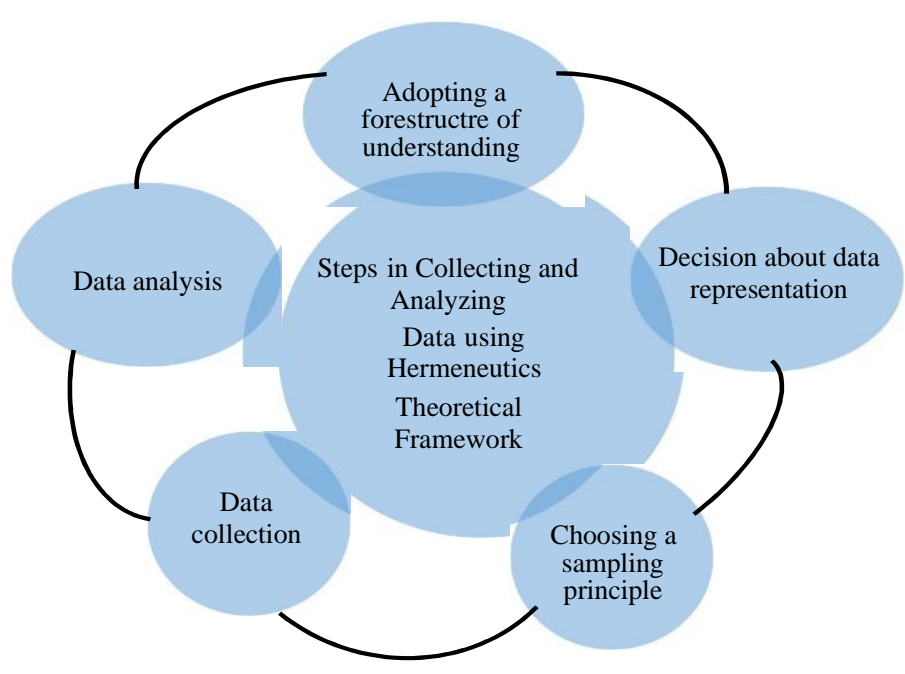

Fig. 1. Data Analysis and Collection following Hermeneutics Theoretical Framework as suggested by Patterson \& William [1] and The Qualitative Research Report.

As shown in Fig. 1, the method starts by adopting a Forestructure of Understanding. Conceptual frameworks usually serve as a guide in collecting data. In hermeneutics, researchers fundamentally aim to develop a 'forestructure of understanding' or an approach to understanding a phenomenon through a comprehensive survey of existing literature relative to the problem under investigation. Developing such however is challenging under the helm of hermeneutics philosophy because a researcher is compelled to understand what has been said about the phenomena in the past while still remaining open to the peculiarity and uniqueness of the phenomenon under investigation including the horizon of meaning as perceived by the respondents in the present time. It is suggested then that researchers carefully design 'forestructure of understanding' in such a way that it plays a permissive rather than a restrictive role. The next step is to decide on data representation. Text, language, meaning, communication, and experience are the core qualitative phenomena of hermeneutics. Researchers have to remember that hermeneutics is inclined on this manner of data representation which compels its advocates that it be done in this manner alone. This is followed by choosing a sampling principle. In hermeneutics, a sampling principle is deemed as a justification of how a particular sample represents the phenomenon under investigation. Although no specific sampling technique or principle is suggested, researchers however are compelled to examine the basic tenets, implications, as well as the limitations of existing and 
competing principles in sampling befitting the phenomenon under study. Oftentimes, the purposive sampling technique is employed in hermeneutics. The fourth step is to collect data. Hermeneutics utilize the constructivists' ontology methods in collecting data which includes in-depth interviews, use of photographs or advertisements, personal narratives, and participant observation. The final step is data analysis. In hermeneutics, data analysis revolves around the so-called organizing system that is developed through analysis and fundamentally aims to identify pre-dominant themes that can be referred to organize, interpret, and present meaningful narrations. These are the steps to be undertaken in developing this system: (1) establish data base by tape recording interviews and transcribe them; (2) develop an indexing system; (3) holistically read the interview for full understanding of the text; (4) identify and marks meaning units within the transcript; (5) develop thematic labels; (6) explain interrelationships among the identified themes; and (7) write a discussion for the interpretation.

\section{DISCUSSIONS}

A good qualitative research work necessitates sound theoretical framework. Hermeneutics is one of the many theoretical frameworks that can be anchored with in this regard. In this paper, the fundamentals of hermeneutics were delved into hoping that the knowledge gained herein most especially by the novice researchers may facilitate in appreciating this framework and eventually use it in an empirical endeavor. Given the broad scope of hermeneutics, I endeavored to focus my synthesis on four core elements which I believe are basic enough for aspirant researchers who wish to use hermeneutics as a method or methodology. These elements include: the historical dimension and the many definitions of hermeneutics, the four philosophical orientations, the key contributors, and the steps that have to be undertaken when using this framework. I argued that hermeneutics is a scientific cum philosophical method of textual interpretation originally intended for the sacred text but has encompassed as well behavioral sciences as time advances.

The four philosophical orientations: hermeneutic divination, reenactment or reproductive hermeneutics, critical hermeneutics, productive or projective hermeneutics as discussed earlier are to my belief the evolution of hermeneutics which explains its development from the time of its inception to how it is perceived today. The key contributors mentioned in the paper on the other hand laid forth their respective arguments on how understanding and interpreting a text must be approached. Each of their arguments were well documented and will provide readers with concise underpinnings behind hermeneutics when it appeared in the circulation in the late 19th century. Finally, the steps pertinent to this method explains how data should be collected and analyzed if an empirical inquest is set in the lens of hermeneutics as a theoretical framework. It is hoped that this paper will provide basic yet powerful insights into anyone else's quest to decipher the nuances pertinent to hermeneutics.

\section{REFERENCES}

[1] Patterson, M. \& William, D. (2004). Collecting and Analyzing Qualitative Data. Hermeneutic Principles, Methods, and Case Examples. Sagamore Publishing, USA. 2004. Richard E. Palmer, Hermeneutics: Interpretation Theory in Schleiermacher, Dilthey, Heidegger, and Gadamer, North Western University Press, Evanston, 1969.

[2] Byrne, Michelle M. (1998). Hermeneutics 101. An Information Analyses. MF01/PC01 Plus Postage. USA.

[3] Crotty, M. (1998). The foundations of social science research. St. Leonards, New South Wales: Allen \& Unwin. 1998.

[4] Shorter Oxford English Dictionary on Historical Principles, Vol. I, New York, 2002

[5] Young, Julian, Heidegger, Philosophy, Nazism, Cambridge University Press, Cambridge, 1997, pp. 3-11.

[6] Russell, R. L. (1988). A Critical Interpretation of Packer's "Hermeneutic Inquiry in the Study of Human Conduct." American Psychologist 43: 130-13 I.

[7] Nicholson, G. (1984). Seeing and reading. Atlantic Highlands, NJ: Humanities Press, Inc.

[8] Arnould, E. J. \& E. Fischer (1994). Hermeneutics and consumer research. Journal of Consumer Research 2 1:55-70.

[9] Connolly, J. M., \&T Keurner (1988). Interpretation, decidability, and meaning. In J. M. Connolly \& T Keurner (eds.), Hermeneutics versus science? Three German views, pp. 1-67. New York: Plenum Press.

[10] The Encyclopedia of Religion, Vol. VI, Collier Macmillan Publishers, London.

[11] Makkreel, R. Dilthey: Philosopher of the Human Studies, Princeton University Press, Princeton, 1993; Jos de Mul, The Tragedy of Finitude: Dilthey's Hermeneutics of Life, Yale University Press, New Haven, 2004.

[12] Graubart, M. (2000). The Philosophy of Jürgen Habermas, in the Library of Living Philosophers Series, edited by Lewis E. Hahn, will be published by Open Court Press.

[13] Grondin, J. (1998). Introduction to Philosophical Hermeneutics, Yale University Press, New Haven, 1998.

[14] Bernstein, R. J. (1986). From hermeneutics to praxis. In B. R Wachterhauser (ed.), Hermeneutics and modern philosophy, pp. 87110. Albany, NY State University of New York Press.

[15] Annells, M. (1996). Hermeneutic phenomenology: Philosophical perspectives and current use in Nursing Research. Journal of Advanced Nursing 23, 705-713.

[16] Weinsheimer, J. \& Marshall D. G. (2004): Truth and Method, Crossroad, New York, 2004.

[17] Weinsheimer, J. (1985): Gadamer's Hermeneutics: A Reading of Truth and Method, Yale University Press, New Haven, 1985.

[18] Wright, K. (1990) Festivals of interpretation: Essays on Hans-Georg Gadamer's Work. New York: State University of New York Press.

[19] Gadamer, Hans-Georg: Truth and Method, Continuum, New York, 2005, pp. xxv-xxvi.

[20] Wright, K. (1990) Festivals of interpretation: Essays on Hans-Georg Gadamer's Work. New York: State University of New York Press.

[21] Stewart, J. (1983). Interpretive listening: An Alternative to Empathy Communication Education 32:379-391.

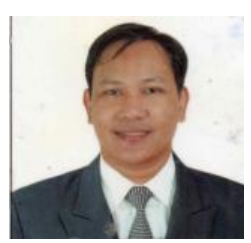

Prof. Mariano D. Gillo teaches Professional Education and Mathematics courses at the College of the Education of the Eastern Visayan State University-Tacloban. where he earned his Master's degree in Instruction and Supervision in 2011. Presently, he is on a dissertation writing for his Doctor of Philosophy in Education major in Research and Evaluation from the University of San Carlos in Cebu City, the Philippines. 